\title{
The effectiveness and effects of alcohol regulation: evidence from India
}

\author{
Dara Lee Luca', Emily Owens ${ }^{2}$ and Gunjan Sharma ${ }^{3 *}$
}

\footnotetext{
* Correspondence:

sharmag4@sacredheart.edu

${ }^{3}$ Sacred Heart University, Fairfield,

USA

Full list of author information is

available at the end of the article
}

\begin{abstract}
We provide quasi-experimental evidence on the effects of alcohol regulation on alcohol consumption and associated public health outcomes using detailed individual level and aggregate data from India, where state-level laws regulating the minimum legal drinking age generate substantial variation in the availability of commercially produced alcohol across people of different ages. We find that despite significant law evasion, men who are legally allowed to drink are substantially more likely to consume alcohol. Further, men who are legally allowed to drink are significantly more likely to commit violence against their partners, suggesting a causal channel between alcohol consumption and domestic violence. These results are robust to the exclusion of states with prohibition, implying that they are driven by differences in MLDA. We also examine the effects of alcohol regulation on other public health outcomes. Consistent with the existing literature, we find evidence that smoking and drinking are complements. Finally, we provide suggestive evidence that stricter alcohol control is associated with lower rates of motor vehicle accidents and crimes against women, but not other forms of crime.
\end{abstract}

Keywords: Alcohol consumption, Domestic violence, Violence against women, Prohibition, Minimum legal drinking age, Smoking, Motor vehicle accidents

JEL Classifications: 118, K42, J120

\section{Introduction}

High rates of alcohol consumption are correlated with adverse outcomes at both individual and societal levels; well-documented examples include increased rates of mortality, injuries, motor vehicle accidents, and criminal activity (Carpenter and Dobkin 2009). The regulation of alcohol consumption in developed countries has been shown to causally affect at least some of these outcomes (Carpenter and Dobkin 2011). However, there is little evidence on the impacts of alcohol regulation in the context of developing countries, where rapidly changing demographic trends and consumption patterns, combined with weaker institutions, warrant a pressing need for a closer examination. Luca et al. (2015) provide suggestive evidence that alcohol prohibition laws in India are effective in reducing consumption even with imperfect implementation and that prohibition significantly reduces intimate partner violence, as well as some other crimes against women. The effectiveness and effects of other (and perhaps less fiscally and politically costly) regulatory measures, such as varying the minimum legal drinking age, however, are still questions in need of answers.

(c) The Author(s). 2019 Open Access This article is distributed under the terms of the Creative Commons Attribution 4.0 International License (http://creativecommons.org/licenses/by/4.0/), which permits unrestricted use, distribution, and reproduction in any medium, provided you give appropriate credit to the original author(s) and the source, provide a link to the Creative Commons license, and indicate if changes were made. 
In this paper, we combine a newly collected set of alcohol regulations-minimum legal drinking age and prohibition status-across states in India to assess their effects on important public health outcomes, including domestic violence, alcohol and tobacco consumption, motor vehicle accidents, and crime. India provides a unique setting to study this question, as it is one of the few countries in the world where there is considerable spatial and temporal variation in alcohol regulation policies across states. A number of states prohibit alcohol consumption altogether, and in others, the minimum legal drinking age (MLDA) varies from 18 to 25 years old. In contrast, previous studies in Western countries have relied on narrower bands of MLDAs: 21 in the USA, 18 or 19 in Canada, 18 in Mexico, or 16 to 18 in Europe (Carpenter and Dobkin 2011). This wider variation allows us to better isolate the impact of the alcohol regulation from the effect of biological aging or other policy factors.

Further, as in many recently developed and developing countries, Indian alcohol policies are still in flux. For example, the state of Mizoram removed prohibition in 2014, the state of Kerela started phasing in prohibition in the same year, and the state of Bihar began enforcing prohibition in 2016. In addition, high-profile cases of drunken driving, murders, and violence against women in India have recently received worldwide attention, with the popular narrative focusing on alcohol consumption and the need for policy interventions. These findings are also relevant for the USA and the developed world, where there has been increasing scrutiny on the connection between drinking and sexual violence, most recently focusing on college campuses (Sampson 2002). ${ }^{1}$

Using micro-level survey data, we first attempt to establish a first-stage relationship between alcohol regulation and consumption in the Indian context. Estimates of this relationship are per se important given the lack of research on the impact of alcohol regulation in the context of developing countries, where costs of alcohol use are arguably larger. ${ }^{2}$ There is also evidence that easily evaded state-level regulations are less effective at reducing alcohol consumption (Dills and Miron 2004; Lovenheim and Slemrod 2010). It follows that an important question facing policy makers in developing countries is whether government regulation is effective at all, particularly in the presence of strong black markets and perceived weaker rule of law relative to the USA or Canada (Allen et al. 2008).

Our data confirm that a large fraction of men under the legal drinking age consume alcohol. In spite of non-trivial law evasion, however, by comparing the prevalence of alcohol consumption among men above and below the drinking age in the same state, and men of the same age across states with different age restrictions governing alcohol sales, we find that regulations reducing access to alcohol are associated with substantive reductions in the consumption of the good in question. Indeed, our results demonstrate while legal access does not determine alcohol consumption absolutely, it does significantly affect the likelihood of alcohol consumption-men who are of legal drinking age are almost 30\% more likely to drink alcohol, which is quite similar to results found in developed countries (e.g., Carpenter and Dobkin 2010). Further, we show that being of legal drinking age is positively linked to smoking, which is consistent with existing literature from developed country settings that drinking and smoking are complements (Decker and Schwartz 2000; Dee 1999).

We then demonstrate that husbands who are legally allowed to drink are both substantially more likely to consume alcohol and commit domestic violence against their 
partners. The results are robust to controlling for a rich set of individual-level characteristics and both observed and unobserved state-level variation. According to a study conducted by the World Health Organization, a third of violent husbands drink, and most of the violence takes place during intoxication. In the USA, close to $40 \%$ of police calls for domestic violence involve alcohol (McClelland and Teplin 2001). Studies of partner violence episodes also indicate that episodes are more severe when the man has been drinking (Leonard and Quigley 1999; McKinney et al. 2010). However, previous studies have found it difficult to disentangle the effects of alcohol consumption from unobserved risk factors that may be both correlated with drinking and violent behaviors. Using exogenous state variation in alcohol regulation, our results provide evidence that drinking may be a causal factor in domestic violence. Our results are robust to the exclusion of dry states (those with a complete prohibition on the consumption of alcohol). Thus, the causal link between alcohol consumption and domestic violence is prevalent in states with MLDA ranging from 18 to 25 . To the extent that a substantively important causal relationship between alcohol consumption and domestic violence exists, alcohol regulation is a potentially promising lever that policy makers could use to reduce violence against women.

We then look at the effects of alcohol control on various public health outcomes using state-year panel data in 16 states between 1980 and 2010 that may be affected by alcohol regulation. Consistent with our analysis using individual-level data, our results using state-year panel data suggest that policies restricting alcohol access may have a secondary social benefit of reducing some forms of violence against women, including molestation, sexual harassment, and cruelty by husband and relatives. At the same time, changes in the MLDA do not appear to be associated with reductions in criminal behavior more broadly. We find suggestive evidence that stricter regulation is associated with lower fatalities rates from motor vehicle accidents and alcohol consumption, but also deaths due to consuming spurious liquor (alcohol that is produced illicitly).

The paper proceeds as follows: in Section 2, we characterize the cultural context and evolution of alcohol consumption and alcohol regulation. We describe how we measure these changes in Section 3. We present our general empirical strategy in Section 4, followed by our individual-level and state-panel results in Section 5. Section 6 concludes.

\section{Institutional setting: cultural and legal attitudes towards alcohol in India}

Compared to the USA, Canada, and the UK, Indian state government regulations provide a compelling large-scale social policy "experiment" in which to examine the consequences of alcohol regulation. The range of alcohol policies vary substantially both across Indian states and within states over time, which we were able to document 19 of the 29 Indian states, where roughly $90 \%$ of the 2001 Indian population lives. Between 1980 and 2008, the time frame for our analysis, the MLDA ranged from 18 to 25 years across the country, and some states had blanket prohibition policies. In addition, we identified six states that changed their MLDA at least once; Bihar increased its MLDA from 18 to 21 in 1985, and Tamil Nadu repealed prohibition and enacted an 18-year-old MLDA in 1990, then subsequently increased it to 21 in 2005. Andhra Pradesh and Haryana both enacted prohibitionary policies in 1995 (the MLDA in Andhra Pradesh had been 21, and 25 in Haryana) only to later repeal them in 1998 and 1999. 
Maharashtra lowered its MLDA to 21 from 25 for 1 year (2005), and Orissa supplanted its 21-year-old MLDA with blanket prohibition in 1994 and 1995.

Several features of Indian society are responsible for these variations in alcohol regulations. Compared to opium and marijuana, alcohol is a relatively less popular intoxicant in India until colonial rule. At the same time that British occupation promoted alcohol use, British MP William S. Caine founded the first prohibitionary organization, the Anglo-Indian Temperance Association (AITA), in 1888. The Indian temperance movement gained considerable strength during the 1920s, such that it led to a considerable decrial of alcohol and its derivatives. The success of the AITA, combined with religious diktats denouncing the sin of intoxication, resulted in a substantial increase in the taxation of such products, with a view to decrease their consumption (Hardiman 2006). The agitation which led to the most decisive political action on the issue was the Gandhian movement; during the struggle for independence in the1940s, temperance came to be closely associated with nationalism. Alcohol consumption was seen as a "Western evil" which distracted the people from their quest for independence (Blocker et al. 2003).

Upon Independence in 1947, temperance was enshrined in Article 47 of the Constitution of India, as a part of the Directive Principles of State Policy, which reads "The State shall regard the raising of the level of nutrition and the standard of living of its people." The prejudice against alcohol remains in modern society, and alcohol is rarely served at any important events (Mohan et al. 2001). Alcohol is also primarily consumed by males; female alcohol consumption is generally uncommon, and alcohol consumption by women outside the home (e.g., in bars or restaurants) is particularly taboo (Benegal et al. 2005).

Upon Independence, Indian states were granted control over policies regulating sales and consumption of alcohol. ${ }^{3}$ Similar to in the USA, variation in alcohol regulation is partly driven by a demand for revenue by individual state governments. Where it is legal, alcohol is taxed heavily at the state level, and Indian states derive around a fifth of their revenue from alcohol taxation-the second largest single source of government funding after sales taxes (Saxena 1999). Moreover, there is a long history in India of a powerful alcohol lobby with industry figures influencing the political process, both in the form of party donations and as representatives (Prasad 2009).

Attitudes towards alcohol consumption in India have more recently evolved in large part due to the combined forces of globalization, prosperity, and changing demographics. Researchers have noted that alcohol consumption has increased dramatically over the past 30 years, and survey evidence suggests that Indians are beginning to drink at ever-younger ages (Mohan et al. 2001; Prasad 2009; Saxena 1999). Problematic drinking is now prevalent in many parts of the country; according to a recent Lancet report, alcohol-related problems account for more than $20 \%$ of hospital admissions, $18 \%$ of psychiatric emergencies, more than $20 \%$ of all brain injuries, and $60 \%$ of all injuries reporting to India's emergency rooms (Prasad 2009). The dynamic push-and-pull of cultural prejudices, changing societal mores, increasing public policy concern over alcohol-related issues, and state incentives to keep alcohol flowing, has led to an amount of flux in alcohol regulation that is not seen in most western countries. 


\section{Data}

\subsection{Data on alcohol regulation in India}

In order to evaluate the effects of alcohol regulation, we compiled a dataset of state-level laws and regulations pertaining to alcohol (sales and/or consumption), with particular attention to MLDAs for the time period 1980-2010 in India. Tracing amendments to minimum drinking age laws over time by state was a complex process. Even the well-known and much used database on Indian law, Manupatra, does not provide a complete chronological list of amendments to national, let alone state, laws. Further, most documentation of the history of state legislation exists only in hard copy in legal libraries. We employed a number of law students from across India to research and summarize the history of alcohol-related legislation in their home state. In this paper, we focus only on the non-price aspect of alcohol regulation, i.e. we do not include analysis on state taxes on alcohol. ${ }^{4,5}$

Based on the legal analysis, we were able to document the historical evolution of MLDA and prohibitionary laws in 18 states from 1980 to 2009, and in 19 states in 1998, 1999, 2005 and 2006. ${ }^{6}$ Figure 1 depicts a map of India with the MLDA in each state that we have information for during this time period. Multiple numbers in a state implies the state has had an MLDA set at each age at some point between 1980 and 2010.

\subsection{Individual-level data on drinking, domestic violence, and smoking}

In order to evaluate the impact of alcohol regulation on individual behaviors, we use the 1998-1999 and 2005-2006 waves of the Indian National Family Health Survey (NFHS). The NFHS is a large-scale, multi-round survey conducted in a representative sample of households throughout India which is intended to provide state- and national-level information for India on a wealth of issues, including consumption of substances such as alcohol and tobacco. This allows us to test whether alcohol control regulations (such as higher MLDAs or prohibition) have a causal effect on alcohol consumption. The link between smoking and alcohol regulation is more complicated and is predicated on whether alcohol and tobacco are substitutes or complements (Decker and Schwartz 2000). If alcohol control regulations reduce drinking, then they will increase (decrease) incidences of smoking if tobacco and alcohol are substitutes (complements).

Importantly, for our purposes, in these waves of the NFHS, a subset of women was asked about their exposure to domestic violence in the previous year and in general. Both waves are intended to produce state- and national-level estimates, and individual responses in both the full survey and domestic violence sample can be weighted to represent all households, or all women in each state.

While the NFHS contains rich household and individual data, we recognize that using self-reported data could be problematic due to underreporting, especially on the topic of domestic violence. ${ }^{7}$ That said, special attention was given to the domestic violence module in the women questionnaire portion of the NFHS. For example, the women's questionnaire (that includes information on violence) is conducted separately from the household survey by trained female interviewers, so that the women have privacy when answering the questions, and the women are also assured that their 


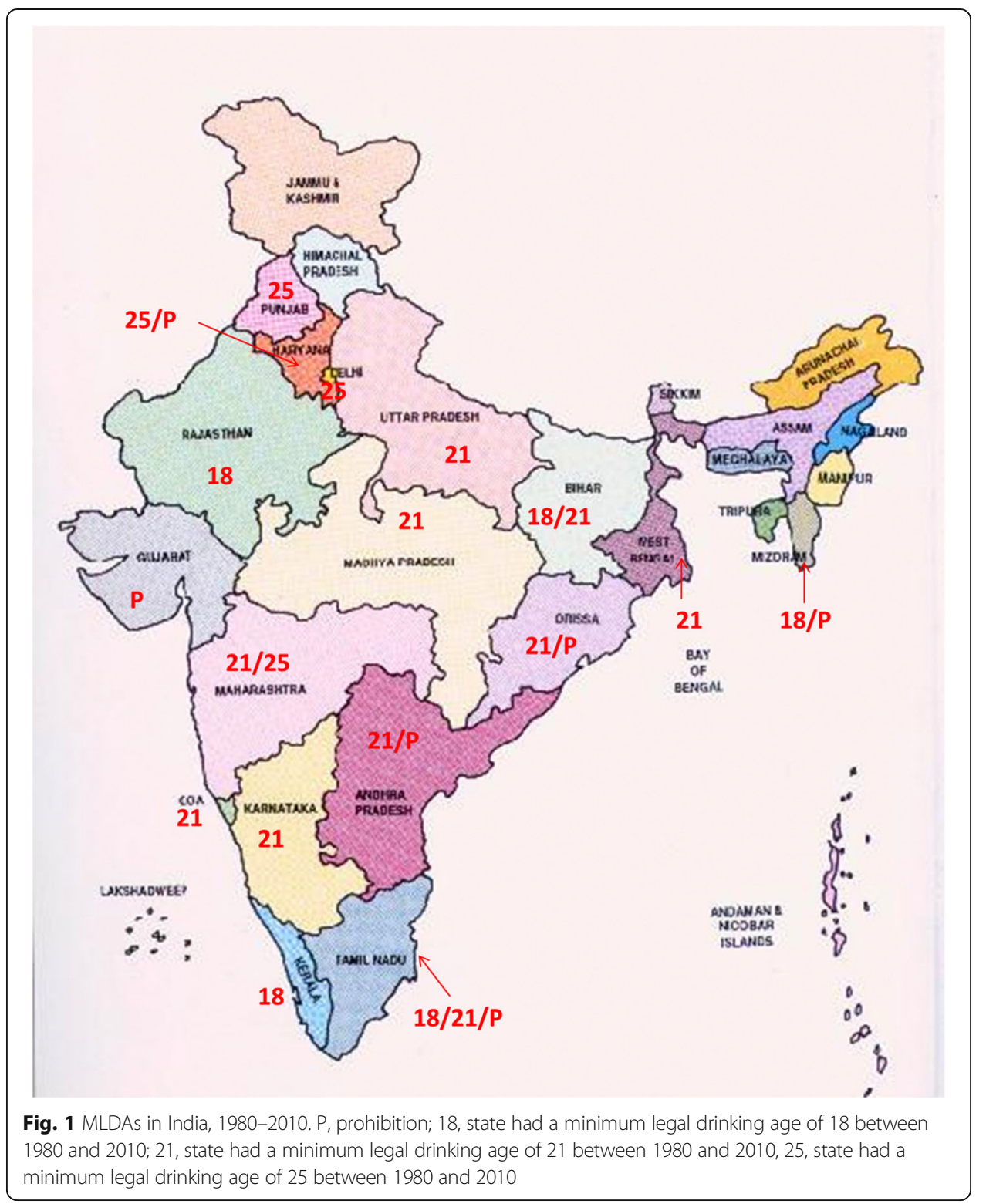

answers will be kept strictly confidential. In the 2005 wave, women were also provided, on request, information on sources of help for abused women. These precautions are in keeping with the World Health Organization's ethical and safety recommendations for research on domestic violence (International Institute for Population Sciences (IIPS) and Macro International 2007).

Table 1 presents summary statistics describing drinking, smoking, domestic violence, and other measures of household and women's status in the NFHS, for both men overall and husbands from ages 15 to 50. The problem of partner abuse appears to be acute in India, but comparable to the likely incidence of domestic violence in the USA. In our data, around $18 \%$ of married women experienced violence at the hands of their husband specifically ${ }^{8}$; a much-cited 1995 survey found that $25 \%$ of women in the USA experienced some form of domestic violence in their lifetime (Tjaden and Thoennes 2000), ${ }^{9}$ and in 2010, the World Health Organization estimated that roughly $38 \%$ of 
Table 1 Summary statistics of key variables in the NFHS

\begin{tabular}{|c|c|c|c|c|c|}
\hline Variable & Mean & $\begin{array}{l}\text { Std. } \\
\text { dev. }\end{array}$ & Min & Max & Obs. \\
\hline \multicolumn{6}{|l|}{ All men (ages 15 to 50) } \\
\hline \multicolumn{6}{|l|}{ Proportion } \\
\hline Drinks & 0.235 & 0.424 & 0 & 1 & 208,356 \\
\hline Smokes & 0.299 & 0.458 & 0 & 1 & 208,362 \\
\hline Chews tobacco & 0.248 & 0.432 & 0 & 1 & 208,360 \\
\hline Can drink legally & 0.478 & 0.500 & 0 & 1 & 208,437 \\
\hline Married & 0.605 & 0.489 & 0 & 1 & 208,091 \\
\hline Hindu & 0.757 & 0.429 & 0 & 1 & 208,091 \\
\hline Muslim & 0.121 & 0.326 & 0 & 1 & 208,091 \\
\hline Age & 29.78 & 10.15 & 15 & 50 & 208,360 \\
\hline Years of schooling & 7.21 & 4.89 & 0 & 24 & 208,141 \\
\hline Household size & 6.558 & 3.518 & 1 & 46 & 208,091 \\
\hline \multicolumn{6}{|l|}{ Husbands (ages 15 to 50 ) } \\
\hline \multicolumn{6}{|l|}{ Proportion } \\
\hline Husband drinks & 0.301 & 0.459 & 0 & 1 & 83,364 \\
\hline Husband smokes & 0.456 & 0.498 & 0 & 1 & 83,364 \\
\hline Wife drinks & 0.021 & 0.142 & 0 & 1 & 83,359 \\
\hline Wife reports domestic violence & 0.179 & 0.384 & 0 & 1 & 83,358 \\
\hline Husband is of legal drinking age & 0.929 & 0.257 & 0 & 1 & 83,364 \\
\hline Urban residence & 0.322 & 0.467 & 0 & 1 & 83,364 \\
\hline $\begin{array}{l}\text { Wife believes that husband is justified in beating spouse if he } \\
\text { suspects her of being unfaithful }\end{array}$ & 0.305 & 0.461 & 0 & 1 & 83,364 \\
\hline Wife has own money that she can control & 0.543 & 0.498 & 0 & 1 & 83,364 \\
\hline Hindu & 0.808 & 0.394 & 0 & 1 & 83,364 \\
\hline Muslim & 0.117 & 0.321 & 0 & 1 & 83,364 \\
\hline Age of husband & 39.7 & 8.818 & 15 & 60 & 83,364 \\
\hline Years of husband's schooling & 5.98 & 5.075 & 0 & 24 & 83,364 \\
\hline Number of children & 2.957 & 1.684 & 0 & 14 & 83,364 \\
\hline Years of wife's schooling & 3.581 & 4.617 & 0 & 23 & 83,364 \\
\hline Age of wife & 33.8 & 8.07 & 15 & 49 & 83,364 \\
\hline Household size & 5.415 & 2.248 & 1 & 35 & 83,364 \\
\hline Ratio of wife's schooling to husband's & 0.898 & 1.146 & 0.01 & 18 & 83,263 \\
\hline Ratio of wife's age to husband's & 0.852 & 0.1 & 0.31 & 1.91 & 83,364 \\
\hline
\end{tabular}

ever-partnered women in South-East Asia experienced some form of intimate partner violence in their lifetime (World Health Organization 2013).

Approximately $30 \%$ of husbands are reported to consume alcohol, which was reported by whoever filled out the household survey in 1998 and by the husband directly in $2005 .{ }^{10}$ Relative to the wives of abstinent husbands, women with drinking husbands were 11 percentage points more likely to also report abuse. Of course, such simple correlations may not represent a causal effect and may also be driven by a particular type of measurement error. In spite of the best efforts of surveyors, it is possible that, in the 1998 wave, women who may be answering both questions systematically misreport 
both alcohol consumption and victimization, both of which are stigmatized behaviors on the part of their husband. The direction of this misreporting is not obvious. On the one hand, reported alcohol consumption might be perceived as an explanation for violence, but on the other hand, people might be more inclined to falsely report positive attributes to "balance out" otherwise negative descriptions of their family. Our identification of the relationship between alcohol consumption, domestic violence, and alcohol regulation is based on the assumption that misreporting of domestic violence and misreporting of alcohol consumption is either conditionally independent of the specific location of a state's MLDA or affect husbands of all ages in a particular state. ${ }^{11}$

\subsection{State-level panel data on crimes and mortality}

We also examine the effects of alcohol control on crimes and important public health outcomes from 1980 to 2010, using administrative state-year panel data from the Indian National Crime Records Bureau (NCRB). There is ample evidence that increased alcohol consumption itself is associated with crime (Carpenter and Dobkin 2011). At the same time, tighter regulations on the sale of alcohol may increase the size of violent black markets. The net effect of alcohol regulation on crime, if that regulation lowers drinking, is therefore an empirical question.

Continuing with our analysis using individual-level data, we first investigate the effects of alcohol regulation on violence against women, focusing on four specific types of crime: rape, sexual molestation, sexual assault, and cruelty by husband and relatives. Next, we turn to other types of violent crimes in India that could be affected by alcohol control, including murder, dacoity (robbery by armed gangs of more than 5 people), robbery, and communal violence (riots). Finally, we investigate the effects of alcohol laws on mortality from injury death, which include fatalities from road accidents, firearms, alcohol consumption, and spurious liquor consumption. These are public health outcomes of policy interest and are included both because they have been the focus of other research on alcohol control and to provide a more complete picture of the impact of alcohol regulation in India.

In addition, we collected data on a host of state-specific time-varying variables that may be correlated with alcohol regulation and crime. These include annual measures of the number of police per capita from the NRCB, and state GDP per capita and government expenditure on education and welfare from the Reserve Bank of India. State-level unemployment rates, urbanization, and literacy rates are interpolated from the Decennial Census of India, collected in 1981, 1991, 2001, and 2011. Table 2 reports key summary statistics for these variables.

\section{Empirical strategy}

Our empirical strategy will be to identify the impact of alcohol control policies on rates of alcohol consumption and other pertinent outcomes using policy variation generated by the regulations governing the legal sale of alcohol in state $s$ in year $t$ : MLDA laws and outright prohibition, which affect whether or not individual $i$ can legally purchase alcohol in his home state. The assumptions necessary to identify the impact of alcohol regulation on drinking and violence vary by data set. 
Table 2 Summary statistics of state-year panel data on crimes, mortality, and controls

\begin{tabular}{|c|c|c|c|c|c|}
\hline Variable & Mean & Std. dev. & Min & Max & Obs. \\
\hline \multicolumn{6}{|l|}{ Crime rates of } \\
\hline Cruelty by husbands and relatives & 436.88 & 379.60 & 0.00 & 1972.47 & 358 \\
\hline Molestation & 340.59 & 249.31 & 7.14 & 1169.66 & 358 \\
\hline Sexual harassment & 111.45 & 278.23 & 0.00 & 2777.26 & 358 \\
\hline Rape & 156.26 & 166.27 & 20.64 & 984.13 & 420 \\
\hline Murder & 339.82 & 164.30 & 98.96 & 1963.11 & 420 \\
\hline Robbery & 210.13 & 138.79 & 4.91 & 961.18 & 420 \\
\hline Communal violence & 1220.4 & 1268.1 & 0 & $10,307.4$ & 420 \\
\hline Dacoity & 88.72 & 133.07 & 0.00 & 2000.00 & 420 \\
\hline Road accidents deaths & 814.78 & 537.42 & 79.49 & 2356.18 & 497 \\
\hline Firearm deaths & 13.32 & 26.88 & 0.00 & 178.45 & 497 \\
\hline Alcohol deaths & 36.73 & 38.36 & 0.00 & 306.36 & 272 \\
\hline Spurious liquor deaths & 12.84 & 21.42 & 0.00 & 236.11 & 450 \\
\hline \multicolumn{6}{|l|}{ Other state characteristics } \\
\hline Literacy rate & 61.55 & 14.34 & 29.27 & 90.92 & 510 \\
\hline Percent urban & 32.82 & 18.31 & 10.47 & 97.50 & 510 \\
\hline GDP per capita & $11,907.46$ & 6834.85 & 1800.00 & $41,487.83$ & 517 \\
\hline Unemployment rate & 2.99 & 2.41 & 0.28 & 14.30 & 510 \\
\hline Police per capita & 1.61 & 1.43 & 0.55 & 10.99 & 480 \\
\hline
\end{tabular}

Underlying data on crime and police per capita are from the National Crimes Records Bureau, 1990-2010. Crime and mortality rates are measured per 10,000 population. State real GDP per capita are from the Reserve Bank of India. Statelevel unemployment rates, urbanization, and literacy rates are interpolated from the Decennial Census of India, collected in 1981, 1991, 2001, and 2011

Our individual-level data only span a short time period during which only three states changed their alcohol regulation. Here, our identification strategy is similar to Carpenter and Dobkin (2009), in that we are comparing the behavior of individuals whose ability to purchase alcohol legally is a discontinuous function of their age, but we are able to exploit additional variation across states in the age at which an individual can legally buy alcohol. Unfortunately, unlike Carpenter and Dobkin (2009), our data do not allow us to implement a true RDD, as we only know the person's age in years and have a limited number of observations around the MLDA thresholds. However, our identification is strengthened by the fact that we are able to exploit the fact that there are four different regimes determining the person's ability to purchase alcohol: age 18 , age 21 , age 25 , and prohibition, so we are better able to disentangle the impact of the age-based alcohol regulation from other influences which vary with age.

Figure 2 depicts the simple means of men between the ages of 15 and 50 who drink, below and above each minimum legal drinking age threshold, alongside the same aged cohorts in prohibition states, giving a coarse sense of the independent impact of age on drinking behavior. Two things are clear: first, that even in dry states, a substantial fraction of men are comfortable reporting alcohol consumption, and second, even in the absence of an age cutoff, older men are more likely to drink. However, it is also evident from the states where the MLDA is 21 or 25 that after husbands reach the drinking age in their state, the fraction consuming alcohol increases relative to same-aged men living in dry states. 


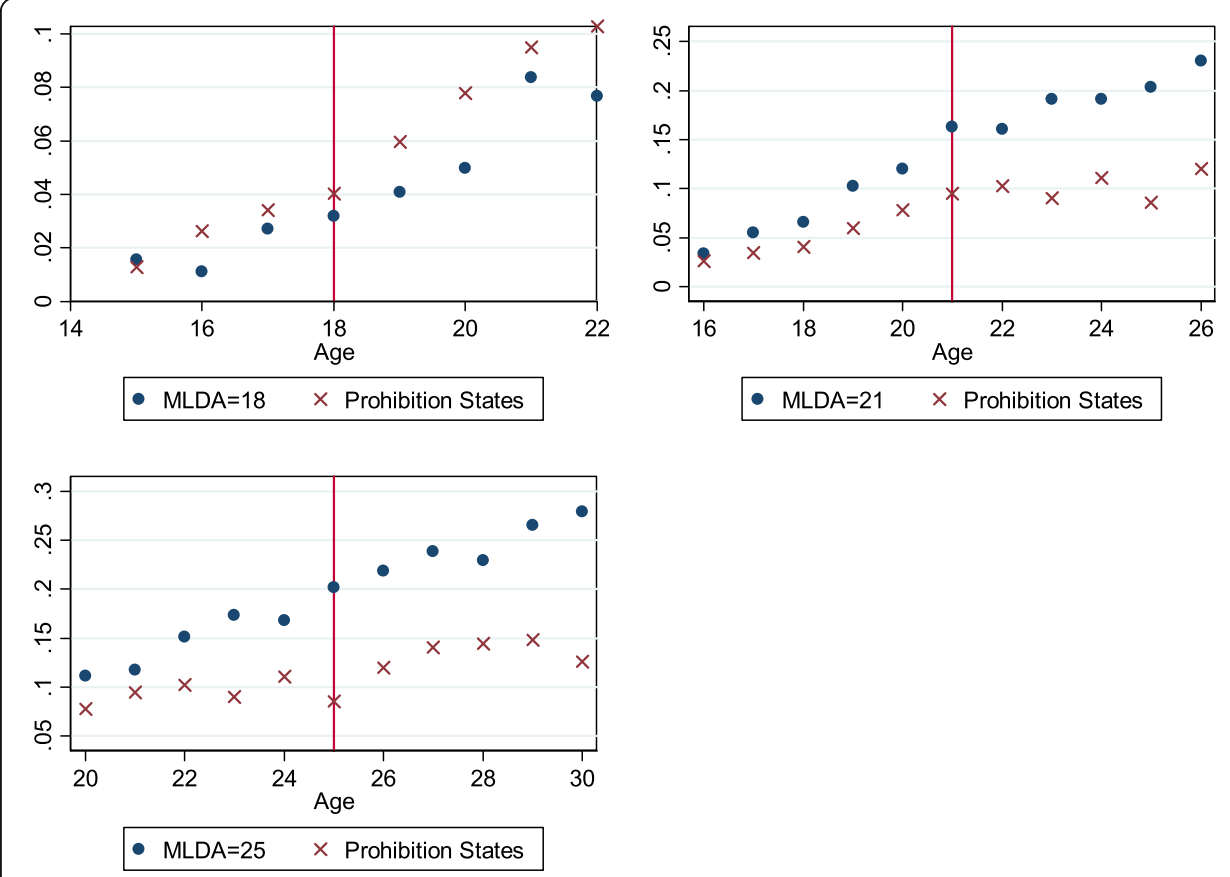

Fig. 2 Fraction of all men who drink, relative to their age in relation to the state's MLDA and same-age cohorts in prohibition states

Based on this suggestive pattern, we can confirm that men who are legally allowed to drink are more likely to consume alcohol by estimating the following linear probability model:

$$
P\left(\text { Outcome }_{i s y}\right)=\delta_{s y}+\operatorname{Legal}_{i s y} \beta^{F S}+X_{i s y} \theta+u_{h s y}
$$

The dependent variable is a binary variable equal to 1 if the man reports drinking alcohol, or one of the other socially relevant outcomes that we observe in the NFHSsmoking or domestic violence (as reported by the man's wife). ${ }^{12}$ The main explanatory variable, Legal, is a binary variable equal to 1 if the man was legally allowed to drink over the past year from the time of the survey interview. ${ }^{13}$ If the state had a blanket prohibition policy in place during the survey year, this value is equal to zero for all men, since no one is legally allowed to purchase alcohol in those states. We include as controls age, education level, employment status, religious affiliation, and family size in the matrix $X_{h s y}$. Luca et al. (2015) directly estimated the impact of blanket prohibition on domestic violence. Here, states under prohibition do not directly contribute to the identification of $\beta^{F S}$, but are used to better pin down the values of $\theta$.

Because we observe both men above and below the drinking age in each of the 19 states represented in this sample, the impact of state-level characteristics that are correlated with the MLDA, such as state alcohol tax rates, are essentially differenced out by state by survey wave fixed effects, $\delta_{s y}$, and do not introduce bias into our estimates, as long as these unobserved variables impact everyone in the state equally. We will allow for arbitrary correlation in the unobserved component of drinking, $u_{h s y}$, within each state. Although clustered standard errors permit heteroskedasticity and within-state error correlation, we may be concerned that the small number of clusters (19) may lead 
to standard errors that are downward biased (Cameron et al. 2008; Donald and Lang 2007). We therefore also present $p$ values produced with wild cluster bootstrapping (Cameron et al. 2008).

Our empirical approach with the primary reduced form estimating equation for our state-level analysis being:

$$
\text { Crime }_{s t}=\gamma_{s}+\delta_{t}+\mathrm{MLDA}_{s t} \beta+X_{s t} \theta+\varepsilon_{s t}
$$

where $\mathrm{MLDA}_{s t}$ is either equal to the MLDA (set to 100 in the case of total prohibition) or a vector of three dummy variables that indicate whether or not 20 year olds are prohibited from purchasing alcohol (meaning the MLDA is 21 or higher), whether or not 24 year olds are prohibited from purchasing alcohol (meaning the MLDA is 25 or higher), and whether or not 30 year olds are prohibited from purchasing alcohol (meaning there is general prohibition). In states where the MLDA is 18 , all three values are equal to 0 , and in states with total prohibition, all values are set to 1 . The matrix $X_{s t}$ includes annual measures of police per capita, the literacy rate, GDP per capita, percent urban, and the percent of government expenditures spent on health and education, and we include $\gamma_{s}$ and $\delta_{t}$ which are state and year fixed effects, respectively. The error term $\varepsilon_{s t}$ is clustered at the state level. Since we are essentially estimating an aggregated version of the individual-level mechanisms (drinking and violence) modeled in Eq. 1, all results are weighted by the annual state population.

Entering the MLDA linearly essentially captures the fact that changing the drinking age from 18 to 25 , or 18 to total prohibition, will have a larger impact on the total amount of alcohol consumption than lowering the drinking age from 25 to 21 . When we relax that parametric assumption, the estimated values of $\beta_{1}, \beta_{2}$, and $\beta_{3}$ represent the net effect of increasingly stringent regulations on alcohol sales.

\section{Results}

\subsection{Alcohol consumption}

As discussed in Section 1, state institutions tend to be weaker in developing countries and attitudes towards alcohol are fundamentally different than in western countries. As a result, it is possible that Indian alcohol regulation may not have a statistically or substantively significant impact on actual alcohol consumption. We present our estimates of Eq. 1 in Table 3.

The baseline regression (column 1) examines the pooled cross-sectional relationship between a man's likelihood to drink and whether he is legally allowed to drink. Without additional controls, men who are of legal drinking age are around 5 percentage points more likely to drink, but the estimate is statistically insignificant. The next column (column 2) adds on state and interview year fixed effects, and the magnitude of the estimate becomes much larger, suggesting that state-specific factors, such as norms about drinking, are correlated with both average individual demand for and legal restrictions on alcohol. In column 3, we control for individual characteristics of the husband that could affect his propensity to drink, including his age, years of schooling, household size, and religion. This doubles the explanatory power of our model, but decreases the magnitude of the estimate back to around 5 percentage points, suggesting that individual characteristics also play a large role in determining alcohol consumption. 
Table 3 The effect of MLDA on drinking and smoking (sample: all men 15-50 years old)

\begin{tabular}{llllll}
\hline & $(1)$ & $(2)$ & $(3)$ & $(4)$ & $(5)$ \\
\hline Panel A: dependent variable_drink alcohol & $0.1143^{* * *}$ & $0.1924^{* * *}$ & $0.0707^{* * *}$ & $0.0713^{* * *}$ & $0.0448^{* * *}$ \\
& $(0.0365)$ & $(0.0159)$ & $(0.0147)$ & $(0.0154)$ & $(0.0073)$ \\
& $\{0.006\}^{++\dagger}$ & $\{0.000\}^{++\dagger}$ & $\{0.0002\}^{++\dagger}$ & $\{0.0002\}^{++\dagger}$ & $\{0.000\}^{++\dagger}$ \\
$N$ & 176,822 & 176,822 & 176,588 & 176,588 & 176,588 \\
R-sq & 0.02 & 0.09 & 0.15 & 0.15 & 0.16 \\
Panel B: dependent variable_smokes & $0.1659^{* * *}$ & $0.2611^{* * *}$ & $0.0557^{* *}$ & $0.0614^{* *}$ & $0.0282^{*}$ \\
& $(0.0401)$ & $(0.0296)$ & $(0.0249)$ & $(0.0255)$ & $(0.0160)$ \\
& $\{0.0007\}^{++\dagger}$ & $\{0.0000\}^{+++}$ & $\{0.0391\}^{++}$ & $\{0.0278\}^{++}$ & $\{0.0949\}^{++}$ \\
$N$ & 176,835 & 176,835 & 176,601 & 176,601 & 176,601 \\
R-sq & 0.03 & 0.09 & 0.19 & 0.19 &
\end{tabular}

Sample includes all men between ages 15 and 50 in NFHS-2 and NFHS-3. Controls for husband include age, years of schooling, whether he belongs to a white-collar occupation, household size, urban residence, religion, and number of children. Controls for wife also include these variables plus, her attitudes towards domestic violence, whether she has money of her own that she controls, and the wife to husband age and schooling ratios. Standard errors presented in parentheses are clustered by state. *Significant at $10 \%,{ }^{* *}$ significant at $5 \%,{ }^{* * *}$ significant at $1 \% . p$ values in braces are adjusted using wild- $t$ bootstrap. ${ }^{\dagger} p \leq 0.1,{ }^{+\dagger} p \leq 0.05,{ }^{++\dagger} p \leq 0.01$

Next, in column 4, we allow for state-by-survey wave fixed effects to account for any state-specific variation over time that may potentially bias our results, such as changes in state alcohol taxes or time-varying state policies to address drinking. In column 5, we enter state-by-age dummies, to allow for potential differential behavior of men of different age groups across states. We find a strong first-stage relationship across most specifications-men who are legally allowed to drink are more likely to report drinking, and the relationship is statistically significant. Given that the mean of alcohol consumption for men in the data is approximately $24 \%$, this 5 percentage point change in likelihood of drinking is substantial, representing a $22 \%$ increase in the likelihood of drinking. ${ }^{14}$

We also examine whether wives are more likely to drink if they are of legal drinking age or if their husbands are of legal drinking age. If lower MLDAs also increase female drinking, our aggregate crime results may reflect a combination of behavioral changes by both men and women caused by alcohol consumption. In addition, if women married to husbands above the drinking age were also systematically more likely to drink, this would suggest that these households were fundamentally different from households with younger husbands. As we show in panel A of Table 7 in Appendix, being of the legal drinking age does not have a measurable effect on women's likelihood of reported drinking; wives of legal drinking age are more likely to drink, but the point estimates are quite small and imprecisely estimated. In panel B, we show that there is also scant evidence that the husband of being of legal drinking age affects the wife's likelihood of drinking. These results help support the hypothesis that alcohol consumption is primarily a male activity and that variation in MLDA is correlated with changes in the prevalence that men consume alcohol. This also suggests that the general stigma of (reported) female alcohol consumption is not directly related to alcohol control policy. 


\subsection{Smoking}

We next examine the impact of alcohol regulation on smoking behavior (panel B, Table 3). Multiple studies of smoking and alcohol consumption in developed countries have found that these are complements (Dee 1999; Decker and Schwartz 2000). Confirming a similar relationship in the context of a developing country is useful for public policy and assessing the full health effects of programs at targeting consumption of either good.

Consistent with the existing research, we find that being legally allowed to drink leads to a statistically significant increase in the likelihood of smoking, suggesting that smoking and drinking are complements. If we use the estimate from our preferred specification (including state-by-wave fixed effects), we find that the likelihood of smoking goes up by 6 percentage points, representing an increase of approximately $20 \%$.

\subsection{Domestic violence}

We then assess the relationship between alcohol regulation and domestic violence. Alcohol consumption may be related to intimate partner violence through multiple channels. Some of these imply minimal scope for alcohol policy to reduce violence against women. For example, if individual preferences for different risky behaviors are positively correlated, people who drink more will also be more likely to engage in violence of all types (Carpenter and Dobkin 2010). Alcohol consumption may also serve as a form of self-medication in response to other life stressors, which themselves might directly cause someone to be violent (Khantzian 1997). However, there is also direct pharmacological effect of drinking on the actions of the drinker-studies in laboratory and experimental settings have thoroughly demonstrated that intoxication leads to increases in aggressive behavior (Bushman 1997). By increasing aggression and heightening emotional responses, alcohol use may increase inter-gender violence. Experiments have shown that alcohol consumption (or either party) increases the negativity of marital conflicts (Leonard and Roberts 1998) and verbal expressions of aggressive intentions among men (Eckhardt 2007). To the extent that a substantively important causal relationship between alcohol consumption and domestic violence exists, alcohol regulation is a potentially promising lever that policy makers could use to reduce violence against women, in contrast to other mechanisms that increase female safety but are more difficult to implement in practice, such as reducing the male-female wage gap (Aizer 2010).

We use the same empirical model on the sample of only husbands and include characteristics of the wife that may influence the likelihood of both drinking and domestic violence, such as the wife's age, education, occupation status, and number of children. These covariates have also been shown to be correlates of domestic violence in other studies (Abramsky et al. 2011, Jewkes 2002). In some specifications, we include variables to capture the degree of the wife's household bargaining power, including whether she has money of her own that she can control and whether she believes that her spouse is justified in beating her if he suspects her of being unfaithful. Aizer (2010) emphasizes that a woman's relative wage-rather than actual wage-determines intra-family bargaining power and partner violence, and so we include proxies for the intra-family wage gap with the age and education gap, which we define in two ways. First, we use the ratio of her age to her husband's age and the ratio of her years of 
schooling to her husband's. Second, we include dummy variables for linear differences in spousal age and years of education, as couples with larger or smaller differences in age or education are potentially very different from couples who are more similar.

The results are reported in Table 4. In panel A, the dependent variable is the likelihood of the husband reporting drinking. In panel B, the dependent variable is the likelihood of the wife reporting domestic violence. As before, the main explanatory variable is a binary variable equal to 1 if the husband was legally allowed to drink over the past year from the time of the survey interview.

The data suggest that the impact of alcohol regulation on drinking does not vary significantly with marital status. Overall, husbands are approximately $23 \%$ more likely to drink if they are legally allowed to drink. Next, we take advantage of the fact that we observe husbands of the same age who may or may not be legally allowed to drink, since the location of the MLDA threshold varies across states, as well as husbands in the same state with different access to alcohol. We examine whether or not there is a differential change in the probability that husbands abuse their wives once men are legally allowed to drink. The results are reported in panel B of Table 4. Column 1 in Table 4 shows a positive correlation between the wife reporting abuse and whether her

Table 4 The effect of MLDA on drinking and domestic violence (sample: all husbands 15-50 years old)

\begin{tabular}{|c|c|c|c|c|c|c|c|}
\hline & $(1)$ & $(2)$ & (3) & (4) & (5) & (6) & (7) \\
\hline \multirow{3}{*}{$\begin{array}{l}\text { Panel A: dependent } \\
\text { variable-husband drinks } \\
\text { alcohol }\end{array}$} & 0.1439 & 0.0419 & 0.0787 & 0.0748 & 0.0732 & 0.0749 & 0.0713 \\
\hline & $(0.0499)^{* * *}$ & $(0.0218)^{*}$ & $(0.0167)^{* * *}$ & $(0.0170)^{* * *}$ & $(0.0172)^{* * *}$ & $(0.0172)^{* * *}$ & $(0.0165)^{* * *}$ \\
\hline & $\{0.112\}$ & $\{0.094\}^{\dagger}$ & $\{0.006\}^{++\dagger}$ & $\{0.006\}^{++\dagger}$ & $\{0.006\}^{++\dagger}$ & $\{0.006\}^{\text {t+† }}$ & $\{0.006\}^{\dagger+\dagger}$ \\
\hline$N$ & 83,364 & 83,364 & 83,364 & 83,263 & 82,728 & 83,263 & 83,364 \\
\hline$R^{2}$ & 0.01 & 0.04 & 0.09 & 0.10 & 0.10 & 0.10 & 0.10 \\
\hline \multirow{3}{*}{$\begin{array}{l}\text { Panel B: dependent } \\
\text { variable-wife reports } \\
\text { domestic violence }\end{array}$} & 0.0854 & 0.0329 & 0.0556 & 0.0525 & 0.0503 & 0.0517 & 0.0486 \\
\hline & $(0.0165)^{* * *}$ & $(0.0245)$ & $(0.0254)^{* *}$ & $(0.0280)^{*}$ & $(0.0268)^{*}$ & $(0.0280)^{*}$ & $(0.0258)^{*}$ \\
\hline & $\{0.106\}$ & $\{0.230\}$ & $\{0.056\}^{\dagger}$ & $\{0.096\}^{\dagger}$ & $\{0.098\}^{\dagger}$ & $\{0.096\}^{\dagger}$ & $\{0.089\}^{\dagger}$ \\
\hline$N$ & 83,358 & 83,358 & 83,358 & 83,257 & 82,723 & 83,257 & 83,358 \\
\hline$R^{2}$ & 0 & 0.03 & 0.06 & 0.06 & 0.06 & 0.07 & 0.07 \\
\hline \multicolumn{8}{|l|}{ Controls } \\
\hline Husband & & & $x$ & $x$ & $x$ & $x$ & $x$ \\
\hline Wife & & & & $x$ & $x$ & $x$ & $x$ \\
\hline Husband/wife ratios & & & & $x$ & & $x$ & \\
\hline \multicolumn{8}{|l|}{ Fixed effects } \\
\hline State & & $x$ & $x$ & $x$ & $x$ & $x$ & $x$ \\
\hline Year & & $x$ & $x$ & $x$ & $x$ & $x$ & $x$ \\
\hline Age gap & & & & & $x$ & & \\
\hline Education gap & & & & & $x$ & & \\
\hline State by survey wave & & & & & & $x$ & \\
\hline State by age gap & & & & & & & $x$ \\
\hline
\end{tabular}

Sample includes husbands between ages 15 and 50 in the NFHS-2 and NFHS-3 waves. Controls for husband include age, years of schooling, whether he belongs to a white-collar occupation, household size, urban residence, religion, and number of children. Controls for wife also include these variables plus, her attitudes towards domestic violence, whether she has money of her own that she controls, and the wife to husband age and schooling ratios. Standard errors presented in parentheses are clustered by state. ${ }^{*}$ Significant at $10 \%,{ }^{*}$ significant at $5 \%,{ }^{* * *}$ significant at $1 \%$. $p$ values in braces are adjusted using wild- $t$ bootstrap. ${ }^{\dagger} p \leq 0.1,{ }^{+\dagger} p \leq 0.05,{ }^{++\dagger} p \leq 0.01$ 
husband is legally allowed to drink, although adjusting for the small number of clusters suggests that the relationship is only marginally precise. In column 2 , we include fixed effects for the state of residence and year of interview, which reduces the magnitude of the effect to around 3 percentage points and is statistically insignificant. In column 3 , we layer on household and husband characteristics, which make the estimated coefficient on Legal both larger and statistically significant, with $p$ values just under $10 \%$. In columns 4 through 7 , we add the wife socio-economic characteristics and bargaining power variables to the regression model.

Across all specifications, the coefficient on Legal is positive, and associated with a 5 percentage point increase in the likelihood that the wife reports being a victim of domestic violence. The precision of this result is somewhat influenced by how we adjust our standard errors to take into the small number of states in our sample, but we are generally able to reject the null hypothesis that a husband's legal access to alcohol is unrelated to his wife's reports of victimization with at least $90 \%$ certainty.

We do not show the coefficients on the control variables for sake of space, but the signs are consistent with expectations and the existing literature on domestic violence. For example, the wife having her own money that she can control is negatively associated with the likelihood of her being beaten by her husband. There is also a positive correlation between domestic violence and whether the wife believes that a husband is justified in beating his wife if he believes her to be unfaithful. ${ }^{15}$ Further, the higher the ratio of the wife's years of schooling to her husband's, the less likely the wife experiences intimate partner violence from her husband; the same goes for age. Relatedly, schooling and occupational status of both spouses are negatively correlated with domestic violence.

The results obtained in this paper are qualitatively similar to the ones obtained in Luca et al. (2015) where the analysis was focused on the effect of outright prohibition on alcohol consumption and domestic violence. Hence, it is reasonable to ask how much of the results of the current analysis are driven by variation in MLDA versus variation in prohibition status. In order to answer this question, we replicate Tables 3 and 4 after excluding states that were ever under prohibition. The results in Appendix Tables 8 and 9 show that variations in MLDAs between 18 and 25 years cause significant changes in alcohol consumption, smoking, and domestic violence. The coefficient estimates are very similar to the ones obtained using all states, with slightly lower precision which is consistent with the smaller number of observations used in this robustness test.

\subsection{Crime}

Do our results on domestic violence extend to other types of violence against women or violent crime in general? As discussed previously, alcohol could be linked to aggressive behavior through multiple channels, such as direct pharmacological effects (Chermack and Taylor 1995). We provide some information on this question using state-year panel data on officially recorded crimes. We then examine whether alcohol regulation affects other types of crime, including murder, dacoity, robbery, and communal riots. Dacoity is an India-specific penal code that refers to armed robbery by a gang of more than five people. Communal riots is a distinct and pervasive feature of Indian public life 
and are often linked to changing political equations and clash of religious sentiments (Krishna 1985). Since there are documented pharmacological effects of alcohol on aggression and inhibition (Miczek et al. 1994), it is worthwhile to investigate whether violent crime rates are affected.

Our estimates of the relationship between MLDA and violence against women are presented in Table 5. With the exception of rape, raising the MLDA is associated with lower rates of violence against women overall, and in particular reported cruelty and sexual harassment. The effects are marginally statistically significant and are substantively small. Since the state-year panel will pick up changes in the behavior of all men, rather than just husbands, it may be the case that there are not enough young husbands to identify the effect of lowering the drinking age from 21 to 18 on drinking or violence. Nonetheless, we find some suggestive evidence that increasing the MLDA

Table 5 The impact of alcohol regulation on crime

\begin{tabular}{|c|c|c|c|c|c|c|c|c|}
\hline & (1) & $(2)$ & (3) & (4) & (5) & (6) & (7) & (8) \\
\hline & \multicolumn{2}{|c|}{ Cruelty, $n=314$} & \multicolumn{2}{|c|}{ Molestation, $n=314$} & \multicolumn{2}{|c|}{ Sexual harassment, $n=314$} & \multicolumn{2}{|c|}{ Rape, $n=395$} \\
\hline \multirow[t]{3}{*}{ MLDA } & -2.80 & & -0.52 & & -1.4347 & & 0.2964 & \\
\hline & $(0.92)^{* * *}$ & & $(0.49)$ & & $(0.51)^{* *}$ & & $(0.1870)$ & \\
\hline & $\{0.145\}$ & & $\{0.354\}$ & & $\{0.079\} \dagger$ & & $\{0.573\}$ & \\
\hline \multirow[t]{3}{*}{ MLDA $\geq 21$} & & -263.49 & & -120.45 & & -132.64 & & 28.70 \\
\hline & & $(104.43)^{* *}$ & & $(24.10)^{* * *}$ & & $(18.91)^{* * *}$ & & $(12.92)^{* *}$ \\
\hline & & $\{0.267\}$ & & $\{0.193\}$ & & $\{0.311\}$ & & $\{0.201\}$ \\
\hline \multirow[t]{3}{*}{ MLDA $\geq 25$} & & 139.80 & & -68.77 & & -33.89 & & -5.00 \\
\hline & & $(53.62)^{* *}$ & & (59.39) & & $(22.99)$ & & $(9.41)$ \\
\hline & & $\{0.252\}$ & & $\{0.501\}$ & & $\{0.339\}$ & & $\{0.661\}$ \\
\hline \multirow[t]{3}{*}{ Prohibition } & & -309.82 & & 26.99 & & -72.14 & & 14.34 \\
\hline & & $(92.59)^{* * *}$ & & $(67.67)$ & & $(27.93)^{* *}$ & & $(8.46)$ \\
\hline & & $\{0.38\}$ & & $\{0.857\}$ & & $\{0.199\}$ & & $\{0.181\}$ \\
\hline \multirow[t]{2}{*}{$R$-sq } & 0.77 & 0.78 & 0.94 & 0.95 & 0.77 & 0.79 & 0.94 & 0.94 \\
\hline & \multicolumn{2}{|c|}{ Murder, $n=395$} & \multicolumn{2}{|c|}{ Dacoity, $n=395$} & \multicolumn{2}{|c|}{ Robbery, $n=395$} & \multicolumn{2}{|c|}{ Riots, $n=395$} \\
\hline \multirow[t]{3}{*}{ MLDA } & 0.033 & & 0.152 & & 0.164 & & 4.18 & \\
\hline & $(0.225)$ & & $(0.206)$ & & $(0.184)$ & & $(1.58)^{* *}$ & \\
\hline & $\{0.903\}$ & & $\{0.559\}$ & & $\{0.385\}$ & & $\{0.257\}$ & \\
\hline \multirow[t]{3}{*}{ MLDA $\geq 21$} & & 58.69 & & -50.02 & & 92.14 & & -317.15 \\
\hline & & $(18.78)^{* * *}$ & & $(25.31)^{*}$ & & (52.63) & & (312.84) \\
\hline & & $\{0.207\}$ & & $\{0.091\} t$ & & $\{0.839\}$ & & $\{0.721\}$ \\
\hline \multirow[t]{3}{*}{ MLDA $\geq 25$} & & 2.94 & & 2.94 & & 26.81 & & 236.39 \\
\hline & & $(19.06)$ & & (27.69) & & $(43.30)$ & & $(122.43)^{*}$ \\
\hline & & $\{0.893\}$ & & $\{0.935\}$ & & $\{0.659\}$ & & $\{0.321\}$ \\
\hline \multirow[t]{3}{*}{ Prohibition } & & -28.42 & & 33.72 & & -55.74 & & 275.49 \\
\hline & & (18.83) & & $(22.18)$ & & (48.95) & & (169.48) \\
\hline & & $\{0.257\}$ & & $\{0.251\}$ & & $\{0.571\}$ & & $\{0.191\}$ \\
\hline$R$-sq & 0.65 & 0.66 & 0.75 & 0.75 & 0.75 & 0.76 & 0.74 & 0.74 \\
\hline
\end{tabular}

All regressions include controls for the state literacy rate, the fraction of people living in urban areas, per capita GDP, the unemployment rate, the number of police per capita, and state and year fixed effects, and are weighted by state population. The omitted minimum legal drinking age is 18 . Standard errors presented in parentheses are clustered by state. ${ }^{*}$ Significant at $10 \%,{ }^{*}$ significant at $5 \%,{ }^{* * *}$ significant at $1 \%$. $p$ values in braces are adjusted for small clusters using wild- $t$ bootstrap. ${ }^{+} p \leq 0.1,{ }^{+\dagger} p \leq 0.05,{ }^{+++} p \leq 0.01$ 
from 18 to 21 will lower most crimes against women, but the estimates are imprecisely estimated (especially when using the wild bootstrap). Overall, our results suggest that prohibition, rather than MLDA laws, may have a larger effect on violence against women.

The pattern between stricter alcohol access and other types of crime is not obvious. Overall, we find a very imprecise, relationship between stricter alcohol control and general forms of violence when the MLDA is entered linearly. A shift from a MLDA of 18 to 21 is linked with a statistically significant decline in dacoity (robbery by armed gangs), and stricter access to alcohol appears to be positively associated with higher incidence of communal violence, but the evidence on other types of crime is otherwise mixed. While we found evidence that higher MLDAs reduced male drinking, this ambiguous impact of overall violence is consistent with stricter alcohol control leading to more dangerous drinking and also with the formation of violent underground markets for alcohol, particularly in states that are completely dry. This type of market-based violence more generally tends to affect men, rather than women (Owens 2014). ${ }^{16}$

\subsection{Other public health outcomes}

Finally, we examine the effects of alcohol regulation on important public health outcomes, as measured by mortality caused by road accidents, firearms, overall alcohol poisoning, and consumption of unregulated alcohol (e.g., home-brewed alcohol) (Table 6). Stricter alcohol regulation is negatively associated with lower mortality from road accidents. However, the estimates do not reach statistical significance $(p=0.15)$. The negative relationship between MLDA and driving accidents is consistent with the literature from the USA (Carpenter and Dobkin 2009; Kaestner and Yarnoff 2011). Most of the existing evidence from developed country settings suggests that the impact

Table 6 The impact of alcohol regulation on mortality

\begin{tabular}{|c|c|c|c|c|c|c|c|c|}
\hline \multirow[b]{2}{*}{ MLDA } & \multicolumn{2}{|c|}{ Road accidents, $n=442$} & \multicolumn{2}{|c|}{ Firearms, $n=442$} & \multicolumn{2}{|c|}{ Alcohol, $n=239$} & \multicolumn{2}{|c|}{ Spurious liquor, $n=399$} \\
\hline & -0.700 & & 0.080 & & -0.104 & & 0.046 & \\
\hline & $(0.510)$ & & $(0.083)$ & & $(0.111)$ & & $(0.051)$ & \\
\hline & $\{0.1558\}$ & & $\{0.419\}$ & & $\{0.395\}$ & & $\{0.455\}$ & \\
\hline MLDA $\geq 21$ & & 8.746 & & 2.119 & & -2.850 & & 7.273 \\
\hline & & $(40.892)$ & & $(3.723)$ & & $(2.117)$ & & $(2.637)^{* *}$ \\
\hline & & $\{0.763\}$ & & $\{0.701\}$ & & $\{0.313\}$ & & $\{0.423\}$ \\
\hline MLDA $\geq 25$ & & -22.068 & & -3.195 & & 26.153 & & -7.965 \\
\hline & & $(43.891)$ & & $(2.698)$ & & $(5.143)^{* * *}$ & & $(11.910)$ \\
\hline & & $\{0.605\}$ & & $\{0.241\}$ & & $\{0.213\}$ & & $\{0.691\}$ \\
\hline Prohibition & & -39.401 & & 8.412 & & -28.846 & & 8.096 \\
\hline & & $(44.141)$ & & $(5.784)$ & & $(6.209)^{* * *}$ & & $(13.171)$ \\
\hline & & $\{0.333\}$ & & $\{0.327\}$ & & $\{0.0299\}+\dagger$ & & $\{0.875\}$ \\
\hline$R$-sq & 0.88 & 0.88 & 0.88 & 0.88 & 0.94 & 0.94 & 0.51 & 0.51 \\
\hline
\end{tabular}

All regressions include controls for the state literacy rate, the fraction of people living in urban areas, per capita GDP, the unemployment rate, the number of police per capita, and state and year fixed effects, and are weighted by state population. The omitted minimum legal drinking age is 18 . Standard errors presented in parentheses are clustered by state. ${ }^{*}$ Significant at $10 \%,{ }^{* *}$ significant at $5 \%,{ }^{* *}$ significant at $1 \%$. $p$ values in braces are adjusted for small clusters using wild- $t$ bootstrap. ${ }^{\dagger} p \leq 0.1,{ }^{+\dagger} p \leq 0.05,{ }^{+\dagger} p \leq 0.01$ 
of higher MLDA would fall mainly on young adults. Hence, our analysis using aggregate data may not pick up the effects of stricter alcohol regimes on specific age groups.

Our results suggest that stricter alcohol regulation is negatively linked to mortality from overall alcohol consumption but possibly higher mortality from consumption of unregulated liquor. That stricter regulation of alcohol is linked with negative health outcomes due to consumption of spurious liquor is consistent with anecdotal evidence, where numerous poisoning cases from consuming liquor produced on the black market have been reported in recent years, with perhaps the most infamous case occurring in 2009 in Gujarat which resulted in 136 deaths. ${ }^{17}$

\section{Discussion}

In this paper, we set out with the goal to investigate the effects of alcohol regulation in the context of India. Specifically, we take advantage of rich individual-level data, staggered timing in age-based alcohol regulation across states, to examine how alcohol control affects drinking, smoking, and domestic violence. We find substantive evidence that reducing access to alcohol through MLDA laws decreases the likelihood of drinking, smoking, and domestic violence. We caveat that these results may not generalize to other developing countries, as India is unique in many aspects, in particular the complicated role of alcohol in society. In this particular case, however, in spite of the generally weak view of legal institutions and perceptions of entrenched government corruption, laws restricting alcohol consumption do appear to influence behavior.

Our first-stage results of higher alcohol consumption by men who are legally allowed to drink are consistent with multiple other studies. Rahman (2003) shows that alcohol prohibition policies in India are associated with a $20-40 \%$ decrease in the probability of alcohol consumption and a $40 \%$ decrease in the quantity of alcohol consumed using household expenditure data. A number of studies have used data from the Monitoring the Future survey, a representative sample of high school seniors from schools across the USA, to demonstrate that government regulation does indeed impact alcohol consumption among youth (Carpenter et al. 2007, Dee 1999, DiNardo and Lemieux 2001). Cook and Moore (2001) find a similar result using data on young adults from the National Longitudinal Survey of Youths. In more recent work, Carpenter and Dobkin (2010) find that individuals in the USA just over age 21 are 31\% more likely to report having recently consumed alcohol and report drinking on almost $60 \%$ more days than individuals just under 21 .

While similar to estimates from the developed world, our results should be interpreted in the context of survey evidence on the role that alcohol consumption plays in Indian society. Recent reports on drinking in India suggest that the signature pattern of alcohol consumption in India is frequent and heavy drinking. More than half of all drinkers fall into the criteria for hazardous drinking, which is characterized by bingeing and solitary consumption to the point of intoxication (Prasad 2009). In the 2005 wave of the NFHS, around $10 \%$ of drinkers report drinking every day, and a third of drinkers consume alcohol more than once a week. Moreover, spirits account for $95 \%$ of the beverages drunk in India. Although we do not have indicators for the quantity of alcohol consumed, it could be that husbands who are reported to drink are more than just casual drinkers. While we are unable to measure binge drinking, we do observe that MLDA laws are likely to promote public health outcomes on at least two dimensions. 
We also provide evidence on the effects of alcohol regulation on a host of other significant public health outcomes. First, our analysis using individual-level data on self-reported smoking behavior suggests that alcohol and tobacco are complements, a finding that is consistent with existing research in developed country settings. Further, we provide suggestive evidence that stricter alcohol regulation reduces some forms of violence against women using both individual and state-year panel data. While there have been a number of papers examining the impact of alcohol regulation on crime, there has been a much smaller body of work focusing on violence against women. Most of these studies examine the impact of alcohol prices on violence against women using variation generated by state excise taxes. Markowitz (2000) examined spousal violence in the USA in the late 1980s. In models with individual fixed effects, she estimated that a $1 \%$ increase in alcohol price would reduce abuse aimed at wives by $5 \%$. She also analyzes US panel data on individuals in the 1990s and finds that higher beer taxes have a (marginally) significant inverse relationship with physical assault but no substantive relationship with rape/sexual assault or robbery. Markowitz (2001) uses two waves of international survey data and finds that these prices exhibit significant negative associations with the rates of assault, robbery, and sexual assault against women in the cross-section but that the associations are no longer statistically significant when country fixed effects are included in the regressions. Durrance et al. (2011) find large positive correlations between alcohol consumption and female homicides at the state level, but focusing only on the plausibly exogenous variation in alcohol consumption driven by excise taxes yields a positive but small and statistically insignificant relationship. Grossman and Markowitz (1999) find that violence on college campuses, including both taking advantage of another person sexually or having been taken advantage of sexually, is inversely related to the price of beer in the state of the college.

Finally, we do not find strong evidence that stricter alcohol regulation affects other types of crime or public health outcomes. We find some suggestive evidence that stricter alcohol regulation is linked to fewer fatalities stemming from motor vehicle accidents and drinking. At the same time, stricter alcohol control is associated with more communal violence and deaths from consuming spurious liquor. However, the precision of our estimates precludes any strong conclusions. The lack of impacts on crime is consistent with the existing mixed evidence from the USA, where "Blue Law" restrictions of the sale of alcohol on Sundays have been found to lower crime (Heaton 2012; Han et al. 2016), but age-based restrictions can be associated with increased aggregate crime, particularly drug offenses (Conlin et al. 2005). At the same time, well-identified research on the impact of alcohol regulation in the USA has found that this type of alcohol regulation can generate statistically and substantively meaningful reductions in violent crime overall (Carpenter and Dobkin 2010, Carpenter et al. 2007). As more, and better quality, survey data on Indian crime and victimization become available, the impacts of alcohol control on violence in developing countries may become clearer.

\section{Endnotes}

${ }^{1}$ Due to a number of high-profile sexual assault cases that involved alcohol, ten schools have enacted alcohol bans in certain settings in order to combat sexual assaults, as many others consider following suit. http://www.cbsnews.com/news/ will-dartmouths-hard-alcohol-ban-make-students-safer/ 
${ }^{2}$ Pre-existing nutritional problems, lack of health care infrastructure, and economic deprivation can aggravate social cost of problematic drinking (Prasad 2009). Poor product regulation can also result in the consumption of low quality or adulterated alcohol, particularly the use of methyl alcohol, which can lead to death or serious organ damage, in particular blindness (Saxena 1999).

${ }^{3}$ The Indian constitution divides important issues and revenue sources into three lists-the Union list (on which the parliament has exclusive power to legislate) contains items like defense, foreign affairs, income taxes, customs duties, corporate taxes etc.; the State list (on which individual states have exclusive authority to legislate and tax) includes public order, police, public health and sanitation, land revenue, taxes on agricultural income, taxes on lands on buildings, estate duty, taxes on electricity, taxes on vehicles, and taxes on luxuries including alcohol; and the Concurrent list (the responsibility for which is shared by the Centre and States) which includes contracts, bankruptcy and insolvency, trustees and trusts, and civil procedure.

${ }^{4}$ The complex nature of state taxes on alcohol in India makes summarizing them in a uniform and comprehensive way across states and time difficult. There are different taxes on different kind of alcohols within and across states (for ex., foreign imported liquor versus domestically produced beer). Duties range from flat-fees to percentages of the manufactured cost, retail price or the government-set market price. Further, the taxes can be levied on different units, ranging from per bulk liter to by proof level (Rahman 2003). Prohibition and alcohol regulations by age, however, are relatively more straightforward. We also include state-by-wave fixed effects in some specifications, which absorb any potential state-time changes in alcohol taxes.

${ }^{5}$ It is possible that increases in the MLDA (fewer men legally allowed to drink) are associated with an increased need for tax revenue (lower taxes on alcohol). It is also possible that increases in MLDA (fewer men legally allowed to drink) correspond with policy shifts towards discouraging alcohol consumption (e.g., via higher taxes). In both these cases, we expect to see reduced rate of alcohol consumption among people eligible to drink, thus biasing our estimates of the impact of MLDAs on drinking towards zero. To the extent that alcohol consumption is a causal driver of domestic violence, we might expect a similar downward bias. Thus, our coefficients provide lower-bounds on the true impact of MLDA on drinking and domestic violence.

${ }^{6}$ These are the major states in India from which reliable data are available. A number of northeastern states such as Nagaland, Manipur, Meghalaya, Assam, Tripura, and Sikkim suffered from insurgency and terrorism issues and many important data collection efforts (including manufacturing and household surveys, economic census etc.) were not conducted for several years.

${ }^{7}$ One must always view self-reports of stigmatized behaviors with some degree of skepticism, as survey respondents may choose to not answer questions, or lie. In either case, we would be more likely to fail to identify any relationship between state policy and outcomes. That is, there would be a downward bias on our coefficient of interestwhether a man is above the legal drinking age. That said, the NFHS contains a large number of variables that are highly sensitive, including information on abortions, infant mortality, contraception, HIV status, and sexual activity, as well as alcohol consumption and exposure to violence. As such, survey takers were both trained and reminded on the survey instruments themselves, to assure the confidentiality of responses (both 
from other family members and third parties like law enforcement), and take active measures to ensure that confidentiality by, for example, checking to make sure that no other people are nearby during the interview.

${ }^{8}$ In 1998, women were asked if their husband had ever beaten them. In 2005, women were asked if their husband ever: slapped them; twisted their arm or pulled their hair; pushed, shook, or threw something at them; punched them; kicked, dragged or otherwise beat them up; tried to choke or burn them on purpose; threatened them with a weapon; physically forced them to have intercourse against their will; and forced them to perform any sexual acts against their will. In our primary results, we identify women as being victims of domestic violence if they answer affirmatively to any of the questions about domestic violence.

${ }^{9}$ We measure domestic violence exposure based on the respondent's yes or no answer to a question about general victimization, rather than an available follow-up question about more recent victimization, for two reasons. First, while there are differences in wording, both waves of the NFHS ask about general exposure to domestic violence in the same, relatively direct way. In 2005, the surveyors were instructed to ask about more recent victimization after a series of other questions about intra-family relationships, making this question difficult to compare to the previous years. Second, respondents are asked about alcohol consumption in general, rather than recent alcohol consumption, so a general question about victimization more explicitly covers the same reference period, with similar recall bias.

${ }^{10}$ This difference in reporting introduces potential survey-to-survey variation that is taken into account with survey wave fixed effects. Alcohol consumption was asked only as a binary variable in the 1998 wave, but both the intensive and extensive margin of consumption was asked in the 2005 wave.

${ }^{11}$ Of course, even though these surveys were anonymous, it is possible that men under the MLDA may be less likely to report that they drink in 2005, biasing these estimates upwards. However, it is less obvious that the household survey respondent in 1998 will respond in the same way.

${ }^{12} \mathrm{We}$ do not instrument for alcohol consumption using husband legality for several reasons. First, because of the relatively low $F$ statistics associated with our estimates of legality and alcohol consumption, the MLDA is unlikely to be a very reliable instrument for alcohol consumption. Second, the exclusion restriction may not hold entirely because the change in alcohol regimes (especially to and from prohibition) could have aggregate impacts on the economy and society that could in turn influence criminal behavior. These effects may be amplified in India given that a large portion of state revenues are derived from alcohol taxes and black markets for liquor are widespread. We hence focus on reduced form effects.

${ }^{13} \mathrm{We}$ also experimented with defining the explanatory variable as whether the husband was ever allowed to drink during the reference period, and the results remain similar.

${ }^{14}$ Data constraints, specifically the relatively small number of observations around the MLDA cutoff and the discrete nature of recorded individual age, preclude implementing a true regression discontinuity design. However, we can roughly approximate the results of such a design by including a fourth-order control for how many years above, or below, the legal drinking age the husband is during the survey year, in 
non-prohibition states. These results, available on request, suggest very large, but also imprecise, positive impacts of legal access to alcohol on both consumption and domestic violence.

${ }^{15}$ The 1998 wave does not contain information on the husband's attitudes towards domestic violence, but to the extent that such attitudes could be endogenously correlated between spouses, we believe the wife's attitude should help capture both her bargaining power within the household as well as the husband's attitude towards domestic violence.

${ }^{16}$ In Appendix Table 10, we present results after excluding states that were ever under prohibition. We find qualitatively similar results. While some coefficient estimates fall, others (e.g., sexual harassment and rape) are larger but less precise. In the case of murder, the coefficient on MLDA is statistically significant at the $5 \%$ level implying that the murder rate is higher in states with a higher MLDA.

${ }^{17}$ The results regarding mortality are qualitatively same, though less precise when we restrict our analysis to the sub-sample of states that were never under prohibition. These results are presented in Appendix Table 11.

\section{Appendix}

Table 7 The impact of alcohol regulation on alcohol consumption of wives

\begin{tabular}{|c|c|c|c|c|c|c|c|}
\hline \multirow[t]{2}{*}{ Dependent variable } & \multicolumn{7}{|c|}{ Wife reports drinking } \\
\hline & $(1)$ & $(2)$ & (3) & (4) & $(5)$ & (6) & (7) \\
\hline \multirow[t]{2}{*}{ 1(wife of legal drinking age) } & $0.0091^{*}$ & $0.0056^{*}$ & 0.0028 & 0.0015 & 0.0024 & 0.0015 & 0.0031 \\
\hline & $(0.0046)$ & $(0.0032)$ & $(0.0028)$ & $(0.0032)$ & $(0.0030)$ & $(0.0031)$ & $(0.0030)$ \\
\hline \multirow[t]{2}{*}{ 1(husband of legal drinking age) } & $0.0115^{*}$ & -0.0039 & -0.0059 & -0.0050 & -0.0063 & -0.0051 & -0.0055 \\
\hline & $(0.0066)$ & $(0.0073)$ & $(0.0064)$ & $(0.0066)$ & $(0.0065)$ & $(0.0066)$ & $(0.0065)$ \\
\hline \multicolumn{8}{|l|}{ Controls } \\
\hline Husband & & & $x$ & $x$ & $x$ & $x$ & $x$ \\
\hline Wife & & & & $x$ & $x$ & $x$ & $x$ \\
\hline Husband/wife ratios & & & & $x$ & & $x$ & \\
\hline \multicolumn{8}{|l|}{ Fixed effects } \\
\hline State & & $x$ & $x$ & $x$ & $x$ & $x$ & $x$ \\
\hline Year & & $x$ & $x$ & $x$ & $x$ & $x$ & $x$ \\
\hline Age gap & & & & & $x$ & & \\
\hline Education gap & & & & & $x$ & & \\
\hline State by survey wave & & & & & & $x$ & \\
\hline State by age gap & & & & & & & $x$ \\
\hline \multicolumn{8}{|c|}{$\begin{array}{l}\text { Underlying data are from the NFHS } 1998 \text { and } 2005 \text { waves. Controls for husband include age, years of schooling, whether } \\
\text { he belongs to a white-collar occupation, household size, urban residence, religion, and number of children Controls for } \\
\text { wife include age, years of schooling, whether she belongs to a white-collar occupation, and number of children. To con- } \\
\text { trol for her household bargaining power, we include her attitudes towards domestic violence, whether she has money of } \\
\text { her own that she controls, and the wife to husband age and schooling ratios } \\
\text { Standard errors presented in parentheses are clustered by state. *Significant at } 10 \% \text {, **significant at 5\%, }{ }^{* * *} \text { significant } \\
\text { at } 1 \%\end{array}$} \\
\hline
\end{tabular}


Table 8 The effect of MLDA on drinking and smoking in states never under prohibition (sample: all men 15-50 years old)

\begin{tabular}{|c|c|c|c|c|c|}
\hline & (1) & (2) & (3) & $(4)$ & (5) \\
\hline \multirow[t]{3}{*}{ Panel A: dependent variable_-drink alcohol } & $0.1112^{* *}$ & $0.1924^{* * *}$ & $0.0646^{* * *}$ & $0.0651^{* * *}$ & $0.0447^{* * *}$ \\
\hline & $(0.0386)$ & $(0.0159)$ & $(0.0136)$ & $(0.0143)$ & $(0.0074)$ \\
\hline & $\{0.0115\}^{\dagger \dagger}$ & $\{0.000\}^{\dagger+\dagger}$ & $\{0.0003\}^{++\dagger}$ & $\{0.0004\}^{++\dagger}$ & $\{0.00002\}^{++\dagger}$ \\
\hline N & 167,068 & 167,068 & 166,838 & 166,838 & 166,838 \\
\hline$R$-sq & 0.02 & 0.09 & 0.15 & 0.15 & 0.16 \\
\hline \multirow[t]{3}{*}{ Panel B: dependent variable_-smokes } & $0.1866^{* * *}$ & $0.2611^{* * *}$ & $0.0535^{* *}$ & $0.0593^{* *}$ & $0.0282^{*}$ \\
\hline & $(0.0424)$ & $(0.0297)$ & $(0.0247)$ & $(0.0253)$ & $(0.0158)$ \\
\hline & $\{0.0005\}^{+\dagger \dagger}$ & $\{0.000\}^{+\dagger}$ & $\{0.0467\}^{+\dagger}$ & $\{0.0332\}^{\dagger+}$ & $\{0.095\}^{\dagger}$ \\
\hline N & 167,082 & 167,082 & 166,852 & 166,852 & 166,852 \\
\hline$R-s q$ & 0.04 & 0.09 & 0.19 & 0.19 & 0.20 \\
\hline
\end{tabular}

Sample includes all men between ages 15 and 50 in NFHS-2 and NFHS-3. Controls for husband include age, years of schooling, whether he belongs to a white-collar occupation, household size, urban residence, religion, and number of children. Controls for wife also include these variables plus, her attitudes towards domestic violence, whether she has money of her own that she controls, and the wife to husband age and schooling ratios. Standard errors presented in parentheses are clustered by state. * Significant at $10 \%$, ** significant at $5 \%$, ${ }^{* * *}$ significant at $1 \%$. $p$ values in braces are adjusted using wild- $t$ bootstrap. ${ }^{\dagger} p \leq 0.1,{ }^{\dagger+} p \leq 0.05,{ }^{+\dagger} p \leq 0.01$

Table 9 The effect of MLDA on drinking and domestic violence in states never under prohibition (sample: all husbands $15-50$ years old)

\begin{tabular}{|c|c|c|c|c|c|c|c|}
\hline & (1) & $(2)$ & (3) & (4) & (5) & (6) & (7) \\
\hline \multirow{3}{*}{$\begin{array}{l}\text { Panel A: dependent } \\
\text { variable-husband drinks } \\
\text { alcohol }\end{array}$} & 0.0341 & 0.0417 & 0.0825 & 0.0739 & 0.0729 & 0.0738 & 0.0712 \\
\hline & $(0.0224)$ & $(0.0221)^{*}$ & $(0.0166)^{* * *}$ & $(0.0168)^{* * *}$ & $(0.0172)^{* * *}$ & $(0.0171)^{* * *}$ & $(0.0168)^{* * *}$ \\
\hline & $\{0.187\}$ & $\{0.099\}^{\dagger}$ & $\{0.004\}^{+\dagger}$ & $\{0.006\}^{\dagger}$ & $\{0.006\}^{\dagger}$ & $\{0.006\}^{\dagger}$ & $\{0.008\}^{\dagger}$ \\
\hline$N$ & 77,941 & 77,941 & 77,291 & 77,769 & 77,425 & 77,769 & 77,769 \\
\hline$R-s q$ & 0.00 & 0.03 & 0.09 & 0.09 & 0.09 & 0.10 & 0.09 \\
\hline \multirow{3}{*}{$\begin{array}{l}\text { Panel B: dependent } \\
\text { variable-wife reports } \\
\text { domestic violence }\end{array}$} & 0.0505 & 0.0328 & 0.0565 & 0.0546 & 0.0516 & 0.0539 & 0.0492 \\
\hline & $(0.0267)^{*}$ & $(0.0248)$ & $(0.0258)^{* *}$ & $(0.0283)^{*}$ & $(0.0269)^{*}$ & $(0.0283)^{*}$ & $(0.0264)^{*}$ \\
\hline & $\{0.0839\}^{\dagger}$ & $\{0.213\}$ & $\{0.0599\}^{\dagger}$ & $\{0.0839\}^{\dagger}$ & $\{0.0899\}^{\dagger}$ & $\{0.0879\}^{\dagger}$ & $\{0.0979\}^{\dagger}$ \\
\hline$N$ & 77,935 & 77,935 & 77,764 & 77,764 & 77,420 & 77,764 & 77,764 \\
\hline$R-s q$ & 0.00 & 0.03 & 0.06 & 0.06 & 0.06 & 0.07 & 0.07 \\
\hline \multicolumn{8}{|l|}{ Controls } \\
\hline Husband & & & $x$ & $x$ & $x$ & $x$ & $x$ \\
\hline Wife & & & & $x$ & $x$ & $x$ & $x$ \\
\hline Husband/wife ratios & & & & $x$ & & $x$ & \\
\hline \multicolumn{8}{|l|}{ Fixed effects } \\
\hline State & & $x$ & $x$ & $x$ & $x$ & $x$ & $x$ \\
\hline Year & & $x$ & $x$ & $x$ & $x$ & $x$ & $x$ \\
\hline Age gap & & & & & $x$ & & \\
\hline Education gap & & & & & $x$ & & \\
\hline State by survey wave & & & & & & $x$ & \\
\hline State by age gap & & & & & & & $x$ \\
\hline
\end{tabular}

Sample includes husbands between ages 15 and 50 in the NFHS-2 and NFHS-3 waves. Controls for husband include age, years of schooling, whether he belongs to a white-collar occupation, household size, urban residence, religion, and number of children. Controls for wife also include these variables plus, her attitudes towards domestic violence, whether she has money of her own that she controls, and the wife to husband age and schooling ratios. Standard errors presented in parentheses are clustered by state. ${ }^{*}$ Significant at $10 \%,{ }^{* *}$ significant at $5 \%$, ${ }^{* * *}$ significant at $1 \% . p$ values in braces are adjusted using wild- $t$ bootstrap. ${ }^{\dagger} p \leq 0.1,{ }^{+\dagger} p \leq 0.05,{ }^{+\dagger+} p \leq 0.01$ 
Table 10 The impact of alcohol regulation on crime in states never under prohibition

\begin{tabular}{|c|c|c|c|c|c|c|c|c|}
\hline & Cruelty, $n=$ & 188 & Molestati & on, $n=188$ & Sexual haras & nent, $n=188$ & Rape, $n=$ & 235 \\
\hline \multirow[t]{3}{*}{ MLDA } & 29.27 & & -0.048 & & -2.89 & & 3.28 & \\
\hline & $(15.61)^{*}$ & & $(3.96)$ & & $(1.71)$ & & $(4.00)$ & \\
\hline & $\{0.385\}$ & & $\{0.959\}$ & & $\{0.605\}$ & & $\{0.519\}$ & \\
\hline \multirow{3}{*}{ MLDA $\geq 21$} & & -601.48 & & -224.68 & & 68.37 & & 18.43 \\
\hline & & $(299.65)^{*}$ & & $(54.33)^{* * *}$ & & $(10.06)^{* * *}$ & & (18.03) \\
\hline & & $\{0.884\}$ & & $\{0.782\}$ & & $\{0.480\}$ & & $\{0.407\}$ \\
\hline \multirow[t]{3}{*}{ MLDA $\geq 25$} & & 117.10 & & -0.19 & & -11.59 & & -5.66 \\
\hline & & $(62.45)^{*}$ & & $(5.87)$ & & $(6.84)$ & & $(10.57)$ \\
\hline & & $\{0.396\}$ & & $\{0.992\}$ & & $\{0.592\}$ & & $\{0.624\}$ \\
\hline \multirow[t]{2}{*}{$R$-sq } & 0.76 & 0.76 & 0.97 & 0.97 & 0.79 & 0.79 & 0.94 & 0.95 \\
\hline & \multicolumn{2}{|c|}{ Murder, $n=235$} & \multicolumn{2}{|c|}{ Dacoity, $n=235$} & \multicolumn{2}{|c|}{ Robbery, $n=235$} & \multicolumn{2}{|c|}{ Riots, $n=235$} \\
\hline \multirow[t]{3}{*}{ MLDA } & 15.67 & & -5.536 & & 48.48 & & -152.78 & \\
\hline & $(6.87)^{*}$ & & (13.806) & & $(13.81)^{* * *}$ & & $(79.95)^{*}$ & \\
\hline & $\{0.0319\}+\dagger$ & & $\{0.739\}$ & & $\{0.179\}$ & & $\{0.293\}$ & \\
\hline \multirow[t]{3}{*}{ MLDA $\geq 21$} & & 61.94 & & -11.94 & & 202.11 & & -780.14 \\
\hline & & $(32.91)^{*}$ & & $(76.04)$ & & $(41.33)^{* * *}$ & & $(234.60)^{* *}$ \\
\hline & & $\{0.172\}$ & & $\{0.937\}$ & & $\{0.193\}$ & & $\{0.241\}$ \\
\hline \multirow[t]{3}{*}{ MLDA $\geq 25$} & & 29.91 & & -32.36 & & 69.61 & & 94.72 \\
\hline & & $(13.74)^{*}$ & & $(27.56)$ & & $(33.95)^{*}$ & & (134.85) \\
\hline & & $\{0.192\}$ & & $\{0.454\}$ & & $\{0.286\}$ & & $\{0.750\}$ \\
\hline$R$-sq & 0.80 & 0.81 & 0.78 & 0.78 & 0.76 & 0.76 & 0.72 & 0.72 \\
\hline
\end{tabular}

Table 11 The impact of alcohol regulation on mortality in states never under prohibition

\begin{tabular}{|c|c|c|c|c|c|c|c|c|}
\hline \multirow[b]{2}{*}{$\overline{\mathrm{MLDA}}$} & \multicolumn{2}{|c|}{ Road accidents, $n=267$} & \multicolumn{2}{|c|}{ Firearms, $n=267$} & \multicolumn{2}{|c|}{ Alcohol, $n=143$} & \multicolumn{2}{|c|}{ Spurious liquor, $n=240$} \\
\hline & -3.795 & & -0.529 & & 5.371 & & 1.826 & \\
\hline & $(16.185)$ & & $(0.883)$ & & $(0.430)^{* * *}$ & & $(0.832)^{*}$ & \\
\hline & $\{0.811\}$ & & $\{0.715\}$ & & $\{0.0399\}^{\dagger} \dagger$ & & $\{0.299\}$ & \\
\hline MLDA $\geq 21$ & & 20.260 & & -2.040 & & 0.733 & & 6.838 \\
\hline & & (92.052) & & $(3.476)$ & & (8.799) & & $(5.681)$ \\
\hline & & $\{0.895\}$ & & $\{0.695\}$ & & $\{0.966\}$ & & $\{0.882\}$ \\
\hline MLDA $\geq 25$ & & -67.115 & & -1.370 & & 21.485 & & 7.304 \\
\hline & & (38.666) & & $(2.413)$ & & $(1.719)^{* * *}$ & & $(3.329)^{*}$ \\
\hline & & $\{0.298\}$ & & $\{0.524\}$ & & $\{0.0309\}^{{ }^{+}}$ & & $\{0.288\}$ \\
\hline$R$-sq & 0.86 & 0.86 & 0.88 & 0.88 & 0.97 & 0.97 & 0.64 & 0.64 \\
\hline
\end{tabular}

All regressions include controls for the state literacy rate, the fraction of people living in urban areas, per capita GDP, the unemployment rate, the number of police per capita, and state and year fixed effects, and are weighted by state population. The omitted minimum legal drinking age is 18 . Standard errors presented in parentheses are clustered by state. ${ }^{*}$ Significant at $10 \%,{ }^{* *}$ significant at $5 \%,{ }^{* * *}$ significant at $1 \%$. $p$ values in braces are adjusted for small clusters using wild- $t$ bootstrap. ${ }^{\dagger} p \leq 0.1,{ }^{\dagger+} p \leq 0.05,{ }^{\dagger+\dagger} p \leq 0.01$ 


\section{Acknowledgements}

We would like to thank the anonymous referee and the editor for the useful remarks. Responsible editor: David Lam.

\section{Funding}

Data collection was enabled by a grant provided by the Cornell Population Center.

\section{Availability of data and materials}

Data on domestic violence, alcohol consumption and smoking behavior used in this paper are available in the repository, https://www.dhsprogram.com/data/available-datasets.cfm.

Data on crime statistics used in this paper are available in the repository, http://ncrb.gov.in/.

Data on minimum legal drinking age in Indian states are available from the corresponding authors on reasonable request.

\section{Competing interests}

The IZA Journal of Development and Migration is committed to the IZA Guiding Principles of Research Integrity. The authors declare that they have no competing interests.

\section{Publisher's Note}

Springer Nature remains neutral with regard to jurisdictional claims in published maps and institutional affiliations.

\section{Author details}

${ }^{1}$ Mathematica Policy Research, Cambridge, USA. ${ }^{2}$ University of California, Irvine, USA. ${ }^{3}$ Sacred Heart University, Fairfield, USA.

Received: 4 September 2018 Accepted: 27 December 2018

Published online: 31 January 2019

\section{References}

Abramsky T, Watts CH, Garcia-Moreno C, Devries K, Kiss L, Ellsberg M, Jansen H, Heise L (2011) What factors are associated with recent intimate partner violence? Findings from the WHO multi-country study on women's health and domestic violence. BMC Public Health 11(1):109

Aizer A (2010) The gender wage gap and domestic violence. Am Econ Rev 100(4):1847-1859

Allen F, Chakrabarti R, De S, Qian J, Qian M (2008) Law, institutions and finance in China and India. In: Eichengreen B, Gupta P, Kumar R (eds) Emerging giants: China and India in the world economy, pp 125-183

Benegal V, Nayak M, Murthy P, Chandra P, Gururaj G, Obot IS, Room R (2005) Women and alcohol use in India. In: Alcohol, gender and drinking problems: perspectives from low and middle income countries, vol 89, p 123

Blocker J, Fahey D, Tyrrel IR (2003) Alcohol and temperance in modern history: an international encyclopaedia, vol 1. ABCCLIO, Santa Barbara

Bushman BJ (1997) Effects of alcohol on human aggression: validity of proposed explanations. In: Galanter M (ed) Alcoholism: alcohol and violence, vol 13. Plenum Press, New York, pp 227-242

Cameron AC, Gelbach JB, Miller DL (2008) Bootstrap-based improvements for inference with clustered errors. Rev Econ Stat 90(3):414-427

Carpenter C, Dobkin C (2009) The effect of alcohol access on consumption and mortality: regression discontinuity evidence from the minimum drinking age. Am Econ J Appl Econ 1(1):164-182

Carpenter C, Dobkin C (2010) Alcohol regulation and crime. In: P. Cook, J. Ludwig, and J. McCrary [eds] Controlling crime: Strategies and tradeoffs. University of Chicago Press, Chicago, pp 291-329

Carpenter C, Dobkin C (2011) The minimum legal drinking age and public health. J Econ Perspect 25(2):133-156

Carpenter CS, Kloska DD, O'Malley P, Johnston L (2007) Alcohol control policies and youth alcohol consumption: evidence from 28 years of monitoring the future. BE J Econ Anal Policy 7(1): 1-21

Chermack ST, Taylor SP (1995) Alcohol and human physical aggression: pharmacological versus expectancy effects. J Stud Alcohol 56(4):449-456

Conlin M, Dickert-Conlin S, Pepper J (2005) The effect of alcohol prohibition on illicit-drug-related crimes. J Law Econ 48(1): 215-234

Cook PJ, Moore MJ (2001) Environment and persistence in youthful drinking patterns. In: J. Gruber [ed] Risky behavior among youths: an economic analysis. University of Chicago Press, Chicago, pp 375-438

Decker SL, Schwartz AE (2000) "Cigarettes and alcohol: substitutes or complements" NBER working paper, p 7535

Dee TS (1999) The complementarity of teen smoking and drinking. J Health Econ 18(6):769-793

Dills A, Miron J (2004) Alcohol prohibition and cirrhosis. Am Law Econ Rev 62:285-317

DiNardo J, Lemieux T (2001) Alcohol, marijuana, and American youth: the unintended consequences of government regulation. J Health Econ 20(6):991-1010

Donald S, Lang K (2007) Inference with difference-in-differences and other panel data. Rev Econ Stat 89(2):221-233

Durrance CP, Golden S, Perreira KM, Cook P (2011) Taxing sin and saving lives: can alcohol taxation reduce female homicides? Soc Sci Med 73(1):169-176

Eckhardt Cl (2007) Effects of alcohol intoxication on anger experience and expression among partner assaultive men. J Consult Clin Psychol 75:61-71

Grossman M, Markowitz S (1999) Alcohol regulation and violence on college campuses. National Bureau of Economic Research Working Paper No. 7129 Cambridge

Han S, Branas CC, MacDonald JM (2016) The effect of a sunday liquor-sales ban repeal on crime: a triple-difference analysis. Alcohol Clin Exp Res 40(5):1111-1121 
Hardiman, D (2006) Histories for the Subordinated. University of Chicago Press, Chicago, p 163

Heaton P (2012) Sunday liquor laws and crime. J Public Econ 96(1):42-52

International Institute for Population Sciences (IIPS) and Macro International (2007) National Family Health Survey (NFHS-3),

2005-06: India, vol 1. IIPS, Mumbai

Jewkes R (2002) Intimate partner violence: causes and prevention. Lancet 359(9315):1423-1429

Kaestner R, Yarnoff B (2011) Long-term effects of minimum legal drinking age laws on adult alcohol use and driving fatalities. J Law Econ 54(2):325-363

Khantzian EJ (1997) The Self-Medication Hypothesis of Substance Use Disorders: A Reconsideration and Recent Applications. Harvard Review of Psychiatry 4(5):231-44.

Krishna G (1985) Communal violence in India: a study of communal disturbance in Delhi. Econ Polit Wkly 20(2), 61-74.

Leonard KE, Quigley BM (1999) Drinking and marital aggression in newlyweds: an event-based analysis of drinking and the occurrence of husband marital aggression. J Stud Alcohol Drugs 60(4):537

Leonard KE, Roberts LJ (1998) Marital aggression, quality, and stability in the first year of marriage: Findings from the Buffalo Newlywed Study. In T. N. Bradbury (Ed.), The developmental course of marital dysfunction. Cambridge University Press, New York, pp 44-73.

Lovenheim MF, Slemrod J (2010) The fatal toll of driving to drink: the effect of minimum legal drinking age evasion on traffic fatalities. J Health Econ 29(1):62-77

Luca DL, Owens EG, Sharma G (2015) Can alcohol prohibition reduce violence against women? Am Econ Rev 105(5):625-629 Markowitz S (2000) The price of alcohol, wife abuse, and husband abuse. South Econ J 67(2):279-303

Markowitz S (2001) Criminal violence and alcohol beverage control: evidence from an international study. In: Grossman M, Hsieh CR (eds) The economics of substance use and abuse: the experience of developed countries and lessons for developing countries. Edward Elgar, UK

McClelland GM, Teplin LA (2001) Alcohol intoxication and violent crime: implications for public health policy. Am J Addict 10: 70-85

McKinney CM, Caetano R, Rodriguez LA, Okoro N (2010) Does alcohol involvement increase the severity of intimate partner violence? Alcohol Clin Exp Res 34:655-658

Miczek KA, DeBold JF, Haney M, Tidey J, Vivian J, Weerts EM (1994) Alcohol, drugs of abuse, aggression, and violence. Understanding and preventing violence, $\mathrm{p} 3$

Mohan D, Chopra A, Ray R, Sethi H (2001) Alcohol consumption in India: a cross-sectional study. In: Demers A, Room R, Bourgault C (eds) Surveys of drinking patterns and problems in seven developing countries. Department of Mental Health and Substance Dependence, World Health Organization, Geneva, pp 103-114

Owens E (2014) The American temperance movement and market-based violence. Am Law Econ Rev 16(2):433-472

Prasad R (2009) Alcohol use on the rise in India. Lancet 373(9657):17-18

Rahman, L. 2003. Alcohol prohibition and addictive consumption in India. Leverhulme Centre for Research on Globalization and Economic Policy (GEP), University of Nottingham

Sampson R (2002) Acquaintance rape of college students. Problem-oriented guides for police series guide 17. US Department of Justice Office of Community Policing Services, Washington

Saxena S (1999) Country profile on alcohol in India. In: Riley L, Marshall M (eds) Alcohol and public health in 8 developing countries. Substance Abuse Department Social Change and Mental Health, World Health Organization, Geneva, pp 37-60

Tjaden P, Thoennes N (2000) Extent, nature, and consequences of intimate partner violence: findings from a National Violence against Women Survey. U.S. Department of Justice Report, NCJ \# 181867

World Health Organization. 2013. Global and regional estimates of violence against women: prevalence and health effects of intimate partner violence and non-partner sexual violence

\section{Submit your manuscript to a SpringerOpen ${ }^{\circ}$ journal and benefit from:}

- Convenient online submission

Rigorous peer review

- Open access: articles freely available online

High visibility within the field

- Retaining the copyright to your article

Submit your next manuscript at $\boldsymbol{\nabla}$ springeropen.com 